\title{
MULTILATERALISMO Y EL PROGRAMA DE DOHA PARA EL DESARROLLO
}

Jorge Arroyo Prado

\section{Resumen}

Al crearse la Organización Mundial de Comercio como sucesora del GATT, prosiguió con la facilitación y liberación del comercio a nivel mundial. En noviembre de 2001 dio inicio a la Novena Ronda en Doha, Qatar, sin embargo hasta la fecha no concluye por la oposición de los países desarrollados a reducir los aranceles a su agricultura y eliminar los subsidios al referido sector. A pesar de ello, los Directores Generales de la OMC abrigan la esperanza de lograr acuerdos que beneficie a los países menos desarrollados.

Palabras Clave: Acuerdo General sobre Aranceles y Comercio (GATT), Organización Mundial de Comercio (OMC), Ronda de Doha, Organización Internacional de Comercio (OIC), Banco Mundial, Fondo Monetario Internacional, Sistema Multilateral del Comercio.

\section{Abstract}

With the creation of the World Trade Organization as GATT's successor, continued facilitation and liberalization of trade worldwide. In November 2001 began the ninth round in Doha, Qatar, however to date do not concludes by opposition from developed countries refusing to reduce their agricultural tariffs and eliminate subsidies to that sector. However, the Directors-General of the WTO are hopeful to reach agreements that benefit the least developed countries.

Key words: General Agreement of Tariffs and Trade (GATT), World Trade Organization (WTO) Doha Round,International Trade Organization (ITO), World Bank, International Monetary Fund (IMF), Trade Multilateral System. 


\section{MULTILATERALISMO}

Con el fin de fomentar el comercio mundial se consideró conveniente la creación de una tercera institución, además del Banco de Reconstrucción y Desarrollo, hoy Banco Mundial (BM) y del Fondo Monetario Internacional (FMI), con el fin de regular la cooperación económica internacional, añadiéndose a las instituciones de Bretton Woods. Es decir, según lo previsto por 50 naciones, el plan completo era crear una Organización Internacional de Comercio (OIC) como organismo especializado de la Naciones Unidas. El proyecto de la Carta de Constitución de la OIC era ambicioso. Además de establecer disciplinas para el comercio mundial contenía también normas sobre empleo, acuerdos sobre productos, prácticas comerciales, restricciones, inversiones internacionales y el trato sobre los servicios. No obstante, la preocupación principal era contrarrestar el exceso de proteccionismo. Es así que se inició con el tema arancelario.

Antes de que la Carta constitutiva fuera definitivamente aprobada, 23 de las 50 naciones participantes decidieron en 1946 celebrar negociaciones para reducir y consolidar los aranceles aduaneros, impulsando el comercio y empezar a reducir las enormes medidas proteccionistas que seguían desde comienzos del decenio de los años 30.

La primera ronda de negociaciones dio origen a 45 concesiones arancelarias que representaban una quinta parte del comercio mundial. Las 23 naciones convinieron en aceptar algunas de las normas comerciales es- tipuladas en el proyecto de Carta de la OIC. El conjunto de las normas comerciales y las concesiones arancelarias pasaron a denominarse "Acuerdo General sobre Aranceles Aduaneros y Comercio" (GATT en Inglés), el mismo que entró en vigor en enero de 1948. Las 23 naciones fueron las "partes contratantes" y fundadoras del GATT. (OMC, 2000: 9).

La carta de la OIC fue finalmente aprobada en una conferencia de las Naciones Unidas sobre Comercio y Empleo, celebrada en La Habana, en marzo de 1948. Sin embargo, su ratificación por algunas legislaturas de las naciones no fue posible; la oposición más importante fue la del Congreso de los Estados Unidos de Norteamérica. En 1950 el gobierno de los Estados Unidos anunció que no pediría al congreso que ratificara la Carta de La Habana, lo que supuso en aquel entonces la muerte de la OIC. No obstante su carácter provisional el GATT continuó como único instrumento multilateral por el que se rigió el comercio internacional desde 1948, hasta el establecimiento de la Organización Mundial del Comercio (OMC), en 1995.

Durante casi medio siglo el texto jurídico básico del GATT siguió siendo, en gran parte, el mismo de 1948. Se hicieron adiciones en forma de acuerdos plurilaterales, es decir de participación voluntaria, y se prosiguió el esfuerzo de la reducción de aranceles. Estos acuerdos se llevaron a cabo en una serie de negociaciones multilaterales llamadas "Rondas", celebradas bajo los auspicios del GATT. Inicial- 
mente las rondas de negociaciones del GATT se concentraron en la reducción de aranceles. Después a mediados del decenio de 1960, en la Ronda Kennedy se aprobaron acuerdos antidumping. La Ronda de Tokio, en el decenio de 1970, además de reducción de aranceles abordó obstáculos técnicos al comercio, las medidas para-arancelarias, los códigos de conducta y se hicieron esfuerzos para mejorar el sistema.

La Ronda Uruguay, llamada así porque se inició en Punta del Este, Uruguay fue la octava y última ronda del GATT y de la mayor importancia, con 123 economías asistentes, ya que dio lugar a la creación de la Organización Mundial de Comercio (OMC) y a un nuevo conjunto de acuerdos. Las negociaciones de esta ronda culminaron el 15 de diciembre de 1993. El Acta final con los acuerdos fue suscrita el 15 de abril de 1994 en Marrakech, Marruecos, y entró en vigor a principios de 1995. Los acuerdos consistieron fundamentalmente en la profundización de lo ya existente en las rondas anteriores del GATT que fueron incorporados a la OMC. Asimismo, hubo acuerdos relacionados a la reforma institucional, sus normas, servicios, la propiedad intelectual, la solución de diferencias, los textiles y la agricultura, con el fin de lograr un comercio fluido sin restricciones, bajo un ordenamiento internacional reconocido por los miembros, con el fin de lograr el crecimiento de las economías y el desarrollo de las naciones. Sin embargo, quedaron puntos pendientes, básicamente relacionados al tema de la agricultura.

\section{E1 Sistema Multilateral del Comercio}

Con la creación de la OMC se logra al fin completar la estructura institucional del "Sistema Multilateral del Comercio", esto es, la ONU, el BM, el FMI y la OMC. Es así que la globalización económica tiene hoy más intervinientes entre los estados nacionales y las empresas. Estas organizaciones han ido adaptando sus funciones para constituirse en interlocutores intermediarios e intermediadores en la relación entre países y entre estos y las empresas.

\section{La Ronda de Doha para el Desarrollo}

La OMC ha continuado, igual que el GATT, con las conferencias ministeriales en Rondas de Negociación. En 1996 se produjo una reunión ministerial en Singapur; en 1998, en Ginebra, donde se trató sobre temas de comercio electrónico; en 1999 en Seattle, también conocida como Ronda del Milenio, con 135 países miembros asistentes. En esta reunión se produjeron protestas masivas (la llamada batalla de Seattle) y varios manifestantes dañaron propiedades y saquearon. Se produjeron daños por millones de dólares en el centro de Seattle, lo que generó un fracaso para la reunión programada de la OMC, por tener que suspenderse. En el 2001 la OMC acuerda lanzar la Ronda de Doha con la presencia de todos los países miembros, en aquellos momentos 135, para tratar básicamente asuntos relacionados a la agricultura; en setiembre de 2003 se reunieron en Cancún en la que no se lograron concluir con acuerdos por la posición del naciente grupo G-20 (integrado por países del Sur), que reclamaron la eli- 
minación de subsidios agrícolas en los países desarrollados. Como expresa Mike Peng (2012:245) numerosos países incumplieron las promesas ofrecidas dos años antes en Doha. La papa caliente resultó ser la agricultura; Australia, Argentina y la mayoría de los países en desarrollo pidieron que Japón, la UE y Estados Unidos redujeran los subsidios agrícolas. Japón rechazó la propuesta de disminuir los aranceles del arroz. La Unión Europea se negó a reducir significativamente los subsidios agrícolas que consumían el $40 \%$ de su presupuesto y los Estados Unidos los incrementó en los hechos.

En diciembre del 2005, la OMC volvió a intentar una nueva reunión de la Ronda de Doha en Hong Kong, siendo ya 153 miembros. En ella, se produjeron algunas declaraciones relacionadas al proteccionismo agrícola y otros, sin llegar a lo reclamado por el grupo G-20, lo que se ha convertido en un nudo muy fuerte. Se propuso que al 2013 deberán eliminarse los subsidios agrícolas, de lo cual Estados Unidos y la Unión Europea están en desacuerdo. Aún no concluye dicha Ronda, principal preocupación del Ex Secretario General Pascal Lamy. El 29 de enero de 2007 se reunieron una veintena de ministros en Ginebra con motivo del Foro Económico Mundial de Davos pero tampoco llegaron a un acuerdo consensuado.

Posteriormente, el 29 de julio de 2008, las negociaciones por salvar la Ronda de Doha tras nueve dias de reuniones colapsaron cuando Estados Unidos y la India no logran encontrar un compromiso sobre medidas destinadas a ayudar a que los países pobres protejan a sus agricultores contra los aumentos de las importaciones. Es indudable que desatar ese nudo sigue siendo un enorme desafio mundial. Por el momento el panorama se encuentra con gran incertidumbre, aunque Pascal Lamy se mantenía optimista. Es así que el 21 y 22 de julio de 2009 se llevó a cabo la reunión de Ministros de Comercio del APEC en Singapur, asistió también el Ex Secretario General de la OMC Pascal Lamy quién en su discurso manifestó la importancia de concluir la Ronda de Doha. Los concurrentes incluyendo los Estados Unidos y la Unión Europea, manifestaron su voluntad de llegar próximamente a un consenso que beneficie a todos los miembros de la OMC.

Es de recordar que la Ronda de Doha, novena negociación comercial multilateral de la historia, comenzó oficialmente dos meses después de los atentados terroristas en EEUU, para reactivar la economía mundial en plena crisis.

Recordemos también que la Ronda de Doha es la ronda de negociaciones comerciales más reciente entre los Miembros de la OMC, que en la actualidad suman 159. Ella tiene por objetivo lograr una importante reforma del sistema de comercio internacional mediante el establecimiento de medidas encaminadas a reducir los obstáculos al comercio y de normas comerciales revisadas. El programa de trabajo abarca unas 20 esferas del comercio. La Ronda se denomina también semioficialmente el "Programa de Doha para el Desarrollo", ya que uno de sus objetivos fundamentales es mejorar 
las perspectivas comerciales de los países en desarrollo

La realidad es que la Ronda no ha podido terminar y fue suspendida oficialmente, acabando con la esperanza de sacar a millones de la pobreza por medio del libre comercio debido a la negativa de varios países industrializados a asumir los compromisos minimos que estas negociaciones les demandan. Ninguna otra razón incide con mayor determinación en el estancamiento actual. La revista Economist la califica como "la mayor amenaza para el sistema comercial multilateral de la posguerra"

Consideramos además que es de suma urgencia frenar el crecimiento de obstáculos técnicos al comercio (OTC), esto es, medidas no arancelarias aplicadas por los países más desarrollados,cuyo freno es sumamente necesario para poder alcanzar un desarrollo inclusivo y sostenible en los países en desarrollo.

El 22 de marzo de 2012, los Miembros de la OMC se comprometieron a examinar nuevos enfoques que podrian hacer progresar las negociaciones sobre la agricultura y, el Presidente John Adank, Embajador de Nueva Zelandia, los instó a que prosiguieran las consultas entre ellos.

Pascual Lamy concluyó su periodo como Secretario General de la OMC el 30 de agosto de 2013, después de luchar incansablemente durante los 4 años que dura su cargo, por concluir la Ronda de Doha satisfactoriamente, aspiraciones que no logró el éxito esperado. Le sucedió en el cargo el brasileño Roberto Azevêdos quien es el sexto Di- rector General de la OMC. Su mandato empieza $1^{\circ}$ de septiembre de 2013.

En una reunión informal del Comité de Negociaciones Comerciales celebrada el 14 de octubre de 2013, el Director General Roberto Azevêdo dijo lo siguiente: "Hoy comienza la cuenta regresiva para identificar todas las 'zonas de aterrizaje' en las tres esferas en las que podriamos obtener resultados en Bali. Dentro de pocas semanas tendremos una idea clara de si se puede conseguir el paquete para Bali o no". Los Presidentes de los grupos de negociación sobre la facilitación del comercio,la agricultura y el desarrollo, así como facilitadores de las cuestiones relacionadas con los países menos adelantados, informaron sobre la situación en las esferas de su competencia. Azevêdo envía un mensaje a los ministros representantes ante la OMC conminándolos a trabajar constructivamente para lograr el éxito en la Conferencia Ministerial de Bali ya que debían estar conscientes de lo que está en juego por lo que tenían una alta responsabilidad ante el mundo.

La Novena Conferencia Ministerial se celebrará en Bali, Indonesia, del 3 al 6 de diciembre de 2013. El martes 3 de diciembre por la tarde tendrá lugar la ceremonia de apertura, los días 4 y 5 de diciembre se llevarán a cabo los trabajos de la Conferencia y el viernes 6 de diciembre se celebrará la ceremonia de clausura. Esperamos que se lleguen a algunos acuerdos que satisfagan las partes, aunque nos encontramos incrédulos por los grandes intereses de los países desarrollados que quieren proteger a sus sectores agrícolas de la 
competencia de productores de costos bajos en las naciones en desarrollo. Charles Hill (2011:205) expresa que la OMC sostiene que "suprimir las barreras arancelarias y los subsidios fomentaría significativamente el comercio general, reduciría los precios para los consumidores y aumentaría el crecimiento económico mundial al liberar los recursos de consumo e inversión para dedicarlos a usos más productivos". De acuerdo a cálculos del Fondo Monetario Internacional, suprimir los aranceles y subsidios a los productos agrícolas elevaría el bienestar económico mundial en 128,000 millones de dólares al año. Otras fuentes sugieren que las ganancias se remontarian hasta los 182,000 millones de dólares. Sin embargo, a pesar de estas cifras, no abrigamos esperanzas que se lleguen a estos acuerdos prontamente.

Mientras tanto, la integración económica bilateral y regional va en ascenso ante el fracaso momentáneo del multilateralismo del comercio mundial. Los grupos regionales se presentan como una amenaza a los fines de la OMC, ya que sus fines abarcan mucho más. Por ejemplo la Unión Europea (UE) ha introducido una moneda común, que se han adherido la mayoría de sus miembros, en la llamada zona euro; también está profundizando mayor cooperación como por ejemplo en seguridad y política exterior, así como en problemas específicos de sus miembros, pero no creemos que la OMC llegará a esos acuerdos. Incluso, es digno de mencionar que la UE se está expandiendo; el 1ro de julio del presente año ha incluido a Croacia, llegando a 28 miembros, y está como candidato Turquía; según manifiesta Daniels (2010:321) "es muy probable que llegue hasta Rusia". En el mundo existen varios grupos regionales con vínculos de cooperación cada vez más fuertes, incluso existen acuerdos de promoción comercial bilaterales, los llamados Tratados de Libre Comercio que irán expandiéndose con otros países. Sin embargo, consideramos que estos grupos y los regionales especialmente podrán contribuir con la OMC, en lo siguiente:

1. La liberalización cada vez más acentuada de los grupos regionales, como un adelanto a lo que persigue la OMC.

2. La flexibilidad de los acuerdos, que puede expandirse a otros grupos regionales llegando a la uniformidad de éstos.

3. El interés de los países menos desarrollados de formar parte de grupos regionales, para lograr una mayor liberalización y cooperación para el libre comercio sin obstáculos.

La OMC, tiene así un gran reto que resolver, sobre todo los desacuerdos y divisiones de los países desarrollados con los países menos desarrollados entre sus miembros. Se suponía que en la Ronda de Doha se llegarian a acuerdos, sobre todo en lo relacionado a los productos agrícolas que es lo más controvertido; pero hasta la fecha se ha fracasado a lo largo de 12 años de reuniones. Veremos en la cita de Bali qué noticias tendremos, esperemos que nuevamente no se acuerden plazos de cumplimiento que no se lleguen a aplicar, como ha sido anteriormente, generando expectativas en los países en desarrollo. 


\section{REFERENCIAS BIBLIOGRÁFICAS}

ARROYO PRADO Jorge, "Introducción al Comercio Internacional". Editorial URP, 2011 Lima, Perú.

DANIELS y Otros, "Negocios Internacionales" Editorial Pearson 12 e. 2010. México

HILL CHARLES "Negocios Internacionales" Editorial McGraw Hill, 8va. Edic. 2011, México.

Organización Mundial de Comercio. "El comercio hacia el futuro" 2da. Edic. 2000, Ginebra. Suiza.

PENG Mike "Negocios Globales" Editorial CENGAGE Learning, 2da. Edic. 2012, México.

www.wto.org Organización Mundial de Comercio 2013

www.Wikipedia, enciclopedia mundial 2013

Lima, octubre de 2013. A2. 